\title{
Profil dari Cortical Visual Impairment di Rumah Sakit Dr. M. Djamil Padang
}

\author{
Kemala Sayuti, Suci Permata Sari
}

\begin{abstract}
Abstrak
Anak-anak dengan cortical visual impairment (CVI) pada umumnya mempunyai hasil pemeriksaan okular yang normal disamping penurunan ketajaman penglihatan dan respon pupil yang normal. Penyebab dari CVI bisa kongenital atau didapat. Penyebab prenatal dan perinatal termasuk hipoksia atau iskemia (periventricular leukomalacia $(P V L)$ adalah bentuk yang paling umum dari kerusakan hipoksia pada bayi prematur dan PVL bisa mengakibatkan cerebral palsy), infeksi intrauteri, perdarahan intrakranial, kelainan struktur sistem saraf pusat, kejang dan hidrosefalus. Penyebab yang didapat termasuk trauma yang tidak disengaja, trauma kepala akibat penganiayaan, infeksi seperti meningitis, ensefalitis dan sepsis. Penelitian ini untuk mendiskripsikan profil kasus CVI di RSUP Dr. M. Djamil Padang dari tahun 2012-2015. Data diperoleh dari rekam medis 26 pasien yang didiagnosa dengan CVI selama 2012-2015. Rasio laki-laki dan perempuan adalah 57,69\%: 42,31\%. Ditemukan kelainan kongenital pada 17 pasien $(65,38 \%)$ dan kelainan yang didapat pada 9 pasien $(34,61 \%)$. Kelainan kongenital yang ditemukan : hipoksia pada 5 kasus ( 1 kasus dengan leucomalacia periventrikular dan 4 kasus dengan cerebral palsy) (29,41\%), kelainan dari struktur sistem saraf pusat pada 4 kasus (23,52\%), kejang pada 4 kasus (23,52\%), perdarahan intrakranial pada 2 kasus $(11,76 \%)$, dan infeksi intrauterin, hidrosefalus 1 kasus untuk masing-masing etiologi $(5,88 \%)$. Kelainan yang didapat adalah meningitis pada 8 kasus (88,89\% dan ensefalitis dalam 1 kasus $(11,11 \%)$. Di RSUP dr. M. Djamil Padang, etiologi kongenital yang paling umum adalah hipoksia dan etiologi yang didapat adalah meningitis.

Kata Kunci : Cortical Visual Impairment, cerebral palsy, meningitis, hipoksia perinatal, leucomalacia periventrikular Abstract

Children with cortical visual impairment (CVI) generally have a normal ocular examination aside from their reduced visual acuity and normal pupillary responses. The causes of CVI can be congenital or acquired. Prenatal and perinatal causes include hypoxia/ischemia (periventricular leukomalacia ( $P V L$ ) is the most common form of hypoxic damage in premature infants and PVL can lead to cerebral palsy), intrauterine infection, intracranial hemorrhage, structural central nervous system abnormalities, seizures, and hydrocephalus. Acquired causes include accidental trauma, abusive head trauma, infections such as meningitis, encephalitis and sepsis. This study to describe profile of CVI cases at Dr. M. Djamil Hospital Padang.We obtained the data from medical record of 26 patient whose diagnosed CVI during January 2012-December 2015.: Male and female ratio was 57,69\%: 42,31\%. We found congenital cases 17 patient $(65,38 \%)$ and acquired cases 9 patient $(34,61 \%)$. The congenital etiology were perinatal hypoxia-ischemia in 5 cases $(19,23 \%)$, seizures in 4 cases $(15,38 \%)$, intracranial haemorrhage in 2 cases $(7,69 \%)$, congenital microchepali in 2 cases (7,69\%), and intrauterine infection, arachnoid cyst, atrophy of the frontal lobes and cerebellum, hydrocephalus 1 cases for each etiology (3,84\%). The acquired etiology were meningitis in 8 cases (30,76\%) and enchepalitis in 1 cases (3,84\%). In Dr. M. Djamil Hospital Padang, the most common congenital etiology was hypoxia and acquired etiology was meningitis.
\end{abstract}

Keywords:Cortical visual impairment, cerebral palsy, meningitis, perinatal hypoxia, periventricular leukomalacia.

Affiliasi penulis : Bagian Mata, Fakultas Kedokteran Universitas Andalas

Korespondensi :Kemala SayutiKemala_sayuti@yahoo.co.id Telp

\section{PENDAHULUAN}

Cortical Visual Impairment (CVI) merupakan penyebab paling umum dari gangguan penglihatan bilateral pada anak-anak di negara berkembang. Meningkatnya insiden CVI di negara berkembang karena meningkatnya tingkat kelangsungan hidup bayi prematur. Sebagai konsekuensinya, menurunnya mortalitas anak dengan masalah medis yang kompleks. $(1,2,3)$

The Blind Babies Foundation of Northern California menemukan bahwa anak-anak dibawah usia 5 tahun dengan gangguan visual, penyebab yang paling menonjol adalah CVI. The Oxford Registry of Early Childhood Impairment menemukan bahwa hampir $30 \%$ dari anak-anak dengan gangguan penglihatan bilateral didiagnosa dengan CVI. Di Liverpool ditemukan bahwa anak-anak dengan gangguan neurologis dan gangguan penglihatan, CVI adalah penyebab yang paling umum. Prevalensi yang dihitung secara konservatif, CVI bertanggung jawab untuk 30\% dari semua kebutaan pada anak di New Zealand, dimana penyebab yang paling umum adalah asfiksia perinatal. Penelitian yang dilakukan di Nordic, kerusakan otak menyebabkan peningkatan jumlah anak dengan gangguan visual. $(1,4,5)$

CVI didefinisikan sebagai kehilangan fungsi visual bilateral terkait dengan kerusakan sistem saraf pusat atau kerusakan jalur visual posterior seperti korpus genikulatum lateral, radiasi optik, korteks visual primer, dan visual association areas sedangkan jalur visual anteriordan anatomi struktur mata normal. $(6,7)$

Etiologi dari CVI bisa kongenital atau didapat. Penyebab prenatal dan perinatal termasuk periventricular leucomalacia (PVL), infeksi intrauterin, hipoksia, perdarahan intrakranial, kelainan struktur sistem syaraf pusat, kejang dan hidrosefalus. Penyebab didapat termasuk trauma karena kecelakaan, abusive head trauma, meningitis dan ensefalitis. Berdasarkan etiologi, gangguan visual pada CVI bisa transient atau permanen dan bisa juga isolated atau terkait dengan berbagai gangguan neurologis. $(8,9)$

Anak dengan CVI pada umumnya mempunyai pemeriksaan struktur okular yang normal disamping penurunan ketajaman penglihatan dan respon pupil yang normal terhadap cahaya. ${ }^{(10,11)}$ 
CVI merupakan kelainan di jalur visual posterior dan sering terkait dengan gangguan neurologis, sehingga pada keadaan tertentu, anakanak dengan $\mathrm{CVI}$ bisa ditemukan gangguan pergerakan okular termasuk strabismus. Strabismus paralitik pada CVI dapat mencerminkan penyakit neurologis yang mendasarinya. Eksotropia konstan pada pasien CVI yang muncul pada tahun pertama kehidupan diduga terjadi karena kerusakan neurologis. Esotropia juga bisa terjadi pada CVI dan mungkin merupakan tanda dari hidrosefalus atau obstruksi dari Ventriculoperitoneal Shunt (VP Shunt). ${ }^{(10)}$

Nistagmus biasanya tidak terjadi pada pasien-pasien dengan CVI, namun pada keadaan tertentu dapat terjadi, terutama jika kehilangan penglihatan yang sangat berat dan ditambah dengan adanya kelainan di jalur visual anterior. ${ }^{(12)}$

Atrofi optik bisa terjadi pada pasien CVI akibat descending optic atrophy atau akibat degenerasi transsynaptic. Jika trauma jalur visual posterior terjadi setelah kelahiran, gambaran dari optik disc tetap tanpa perubahan karena degenerasi transsynaptic tidak terjadi setelah kelahiran. Namun, apabila cedera in utero atau trauma mengenai jalur visual anterior dan posterior sering mengakibatkan hipoplasia nervus optikus atau atrofi optik. $(8,11)$

Sejumlah tekhnik imaging berguna untuk mengidentifikasi penyebab dari CVI. Imaging yang paling sering digunakan adalah ultrasonography (USG), computed tomography (CT), dan magnetic resonance imaging (MRI). (10)

Rehabilitasi visus sangat penting secara komprehensif dan harus direkomendasikan ketika anak mempunyai gangguan visual yang berefek kepada kemampuan mereka untuk melakukan tugas tugas visual. Rehabilitasi visus pada beberapa anak dengan CVI dapat meningkatkan fungsi visual mereka, yaitu dengan cara menggunakan mainan yang bercahaya di ruangan gelap, kotak dengan cahaya yang terang, menggunakan mainan dengan warnawarna cerah dan mengeluarkan suara. ${ }^{(8,13)}$

Prognosis pada pasien CVI tergantung oleh banyak faktor, termasuk penyebab, usia saat onset, keparahan dan jenis kerusakan di otak. Kelainan neurologis terkait juga merupakan faktor penting yang harus dipertimbangkan dalam menentukan prognosis. $(1,10)$

Diagnosa banding dari CVI bervariasi, yaitu termasuk kondisi dimana anak tertunda kematangan visusnya (delayed visual maturation), memiliki respon motorik yang buruk (okulomotorius apraxia) atau tidak memiliki ketertarikan terhadap lingkungan sekitar yang mungkin terlihat pada autis. $(1,14)$

\section{TUJUAN}

Mengetahui profil pasien CVI di RSUP dr. M. Djamil Padang dan untuk mengetahui distribusi frekuensi pasien CVI berdasarkan umur, jenis kelamin, etiologi, gangguan okular dan gangguan neurologis yang menyertainya dan berdasarkan gambaran CT scan kepala di RSUP dr. M. Djamil Padang.

\section{METODE PENELITIAN}

Metode penelitian yang digunakan adalah studi retrospektif deskriptif. Data pasien di peroleh dari rekam medis pasien yang didiagnosa dengan CVI di RSUP dr. M. Djamil dari bulan Januari 2012 Desember 2015. Semua anak yang diduga dengan riwayat gangguan jalur visual posterior diperiksa oleh oftalmologis dengan melakukan evaluasi komprehensif untuk menilai perilaku dan fungsi visual, reaksi pupil, ada atau tidak adanya strabismus, nystagmus dan atrofi optik. Diagnosa CVI didasarkan pada pemeriksaan mata yang memperlihatkan gangguan fungsi penglihatan bilateral dengan adanya riwayat faktor resiko CVI sedangkan jalur visual anterior dan anatomi struktur okular normal.

Setiap rekam medis ditinjau untuk mengidentifikasi informasi demografis seperti jenis kelamin, usia saat didiagnosis, dan etiologi dari CVI tersebut. Hasil CT scan kepala juga dinilai untuk melihat korelasi dengan fungsi visual dan temuan klinis.

\section{HASIL PENELITIAN}

Selama periode Januari 2012 - Desember 2015 terdapat 26 pasien yang di diagnosa dengan CVI di RSUP dr. M. Djamil Padang. Dari 26 pasien ini, 2 pasien $(7,62 \%)$ yang lahir prematur, dan 24 pasien $(92,30 \%)$ yang lahir matur.

Tabel 1. Distribusi frekuensi pasien CVIberdasarkan usiadan jenis kelamin di RSUP dr. M. Djamil Padang.

\begin{tabular}{cccc}
\hline $\begin{array}{c}\text { Rentang } \\
\text { usia } \\
\text { (bulan) }\end{array}$ & $\begin{array}{c}\text { Jumlah } \\
\text { Laki-laki }\end{array}$ & Perempuan & $\begin{array}{c}\text { Jumlah dan } \\
\text { Persentase }\end{array}$ \\
\hline $0-12$ & 8 & 7 & $15(57,69 \%)$ \\
$13-24$ & 3 & 4 & $7(26,92 \%)$ \\
$25-36$ & 3 & - & $3(11,53 \%)$ \\
$37-48$ & - & - & 0 \\
$49-60$ & 1 & - & $1(3,84 \%)$ \\
Total & 15 & $11(42,31 \%)$ & $26(100 \%)$ \\
& $(57,69 \%)$ & & \\
\hline
\end{tabular}

Pada tabel satu dapat dilihat rentang usia pasien dari 1 - 60 bulan, dengan usia yang paling banyak 0-12 bulan sebanyak $15(57,69 \%)$ pasien. Selain itu, pada tabel satu juga dapat dilihat distribusi pasien CVI di RSUP dr. M. Djamil Padang berdasarkan jenis kelamin, dimana angka kejadian CVI lebih banyak pada laki-laki daripada perempuan.

Tabel 2. Distribusi frekuensipasien CVI berdasarkanetiologi di RSUP dr. M. Djamil Padang. Etiologi CVI Jumlah dan Persentase

\begin{tabular}{|c|c|c|}
\hline \multirow[t]{8}{*}{ Kongenital : } & $\begin{array}{l}\text { Hipoksia- } \\
\text { iskemia } \\
\text { perinatal }\end{array}$ & $5(19,23 \%)$ \\
\hline & Kejang & $4(15,38 \%)$ \\
\hline & $\begin{array}{l}\text { Perdarahan } \\
\text { intrakranial }\end{array}$ & $2(7,69 \%)$ \\
\hline & $\begin{array}{l}\text { Kongenital } \\
\text { mikrosefali }\end{array}$ & $2(7,69 \%)$ \\
\hline & $\begin{array}{l}\text { Infeksi } \\
\text { intrauterine }\end{array}$ & $1(3,84 \%)$ \\
\hline & Kista arachnoid & $1(3,84 \%)$ \\
\hline & $\begin{array}{l}\text { Atrofi lobus } \\
\text { frontal dan } \\
\text { serebelum }\end{array}$ & $1(3,84 \%)$ \\
\hline & Hidrosefalus & $1(3,84 \%)$ \\
\hline \multirow[t]{3}{*}{ Didapat: } & Meningitis & $8(30,76 \%)$ \\
\hline & Ensefalitis & $1(3,84 \%)$ \\
\hline & Total & $26(100 \%)$ \\
\hline
\end{tabular}


Etiologi dari CVI terlihat pada tabel 2. Penelitian ini menemukan etiologi kongenital sebanyak 17 pasien $(65,38 \%)$ dan etiologi didapat sebanyak 9 pasien (34,61\%). Dari 26 pasien CVI, etiologi yang paling banyak yaitu meningitis sebanyak 8 pasien (30,76\%), diikuti dengan hipoksia-iskemia perinatal sebanyak 5 pasien $(19,23 \%)$, kejang sebanyak 4 pasien $(15,38 \%)$, perdarahan intrakranial sebanyak 2 pasien $(7,69 \%)$, kongenital mikrosefali sebanyak 2 pasien $(7,69 \%)$, dan infeksi intrauterine, kista arachnoid, atrofi lobus frontal dan serebelum, hidrosefalus, ensefalitis masing-masing 1 pasien $(3,84 \%)$.

Tabel 3. Distribusi frekuensipasien CVI berdasarkangangguan okular yang menyertainya di RSUP dr. M. Djamil Padang.

\begin{tabular}{|c|c|c|}
\hline \multicolumn{2}{|c|}{ Gangguan ocular } & \multirow{2}{*}{$\begin{array}{c}\begin{array}{c}\text { Jumlah dan } \\
\text { persentase (\%) }\end{array} \\
4(15,38 \%)\end{array}$} \\
\hline $\begin{array}{l}\text { Ditemukan } \\
\text { gangguan }\end{array}$ & $\begin{array}{l}\text { Atropi optik } \\
\text { bilateral }\end{array}$ & \\
\hline & Nistagmus & $2(7,69 \%)$ \\
\hline & $\begin{array}{l}\text { Eksotropia } \\
\text { unilateral }\end{array}$ & $1(3,84 \%)$ \\
\hline $\begin{array}{l}\text { Tidak } \\
\text { ditemukan } \\
\text { gangguan } \\
\text { okular: }\end{array}$ & - & $19(73,07 \%)$ \\
\hline Total & & $26(100 \%)$ \\
\hline
\end{tabular}

Dari 26 pasien CVI hanya 7 pasien $(26,92 \%)$ yang ditemukan dengan gangguan okular dan 19 pasien $(73,07 \%)$ tidak ditemukan gangguan okular, yang terlihat pada tabel 3. Gangguan okular yang ditemukan pada penelitian ini yaitu atrofi optikpada 4 pasien $(15,38 \%)$, nistagmus pada 2 pasien $(7,69 \%)$ dan strabismus khususnya eksotropia pada 1 pasien $(3,84 \%)$.

Tabel 4. Distribusi frekuensipasien CVI berdasarkangangguan neurologis yang menyertainya di RSUP dr. M. Djamil Padang.

\begin{tabular}{lll}
\hline \multicolumn{2}{c}{ Gangguan neurologis } & $\begin{array}{l}\text { Jumlah dan } \\
\text { persentase (\%) }\end{array}$ \\
\hline $\begin{array}{l}\text { Ditemukan } \\
\text { gangguan } \\
\text { Neurologis : }\end{array}$ & Epilepsi & $7(26,92 \%)$ \\
& Cerebral Palsy & $4(15,38 \%)$ \\
& Mikrosefali & $2(7,69 \%)$ \\
Tidak & - & $13(50 \%)$ \\
ditemukan & & \\
$\begin{array}{l}\text { Gangguan } \\
\text { neurologis : }\end{array}$ & \\
Total & $26(100 \%)$ \\
\hline
\end{tabular}

Pada penelitian ini, gangguan neurologis yang menyertai pasien CVI ditemukan pada $13(50 \%)$ pasien, dari 26 pasien $\mathrm{CVI}$, yang terlihat pada tabel 4 . Gangguan neurologis yang paling sering ditemukan adalah epilepsi yaitu pada 7 pasien $(26,92 \%)$, cerebral palsy terlihat pada 4 orang pasien $(15,38 \%)$ dan mikrosefali terlihat pada 2 orang pasien $(7,69 \%)$.

Tabel 5. Distribusi gambaran CT scan kepalapada pasien CVI di RSUP dr. M. Djamil Padang.

$\begin{array}{cl}\text { Gambaran } & \text { Jumlah dan } \\ \text { CT scan kepala } & \text { Persentase }\end{array}$

\begin{tabular}{|c|c|c|}
\hline & & (\%) \\
\hline \multirow{9}{*}{$\begin{array}{l}\text { Dilakukan } \\
\text { pemeriksaan } \\
\text { CT scan : }\end{array}$} & Brain Atrophy & $6(23,07 \%)$ \\
\hline & Mikrosefali & $2(7,69 \%)$ \\
\hline & $\begin{array}{l}\text { Hipoksia } \\
\text { Iskemik } \\
\text { Ensefalopati }\end{array}$ & $1(3,84 \%)$ \\
\hline & $\begin{array}{l}\text { Perdarahan } \\
\text { intrakranial }\end{array}$ & $1(3,84 \%)$ \\
\hline & Hidrosefalus & $1(3,84 \%)$ \\
\hline & $\begin{array}{l}\text { Periventrikel } \\
\text { leukomalacia }\end{array}$ & $1(3,84 \%)$ \\
\hline & $\begin{array}{l}\text { Kista } \\
\text { Arachnoid }\end{array}$ & $1(3,84 \%)$ \\
\hline & $\begin{array}{l}\text { Edema } \\
\text { serebri }\end{array}$ & $1(3,84 \%)$ \\
\hline & $\begin{array}{l}\text { Cystic } \\
\text { enchephalom } \\
\text { alacia }\end{array}$ & $1(3,84 \%)$ \\
\hline $\begin{array}{l}\text { Tidak dilakukan } \\
\text { Pemeriksaan CT } \\
\text { scan : }\end{array}$ & - & $11(42,30 \%)$ \\
\hline Total & & $26(100 \%)$ \\
\hline
\end{tabular}

Penelitian ini juga mengevaluasi gambaran CT scan kepala yang dilakukan pada pasien CVI yang terlihat pada tabel 5 . Lima belas pasien $(57,69 \%)$ dari 26 pasien CVI dilakukan pemeriksaan CT Scan pada saat mendiagnosa. Kelainan $C T$ scan yang paling banyak ditemukan adalah brain atrophy sebanyak 6 pasien $(23,07 \%)$, mikrosefali sebanyak 2 pasien $(7,69 \%)$. Kemudian diikuti dengan hipoksia iskemik ensefalopati, perdarahan intrakranial, hidrosefalus, PVL, kista arachnoid, edema serebri, dan cystic enchephalomalacia masing-masing satu pasien $(3,84 \%)$.

\section{DISKUSI}

Prevalensi CVI pada masa anak-anak terus meningkat selama beberapa dekade terakhir ini, hal ini disebabkan karena kemajuan dalam perawatan perinatal. CVI merupakan penyebab paling umum dari bilateral visual impairment pada anak-anak di negara berkembang. (7)

Selama periode Januari 2012 - Desember 2015 terdapat 26 pasien yang diagnosa dengan CVI di RSUP dr. M. Djamil Padang. Diagnosa CVI didasarkan pada pemeriksaan mata yang memperlihatkan fungsi penglihatan bilateral yang jelek dengan jalur visual anterior dan anatomi struktur okular normal, dan kelainan berada di jalur visual posterior. ${ }^{(6,7)}$

Distribusi pasien CVI berdasarkan usia dan jenis kelamin di RSUP dr. M. Djamil Padang pada penelitian ini dapat dilihat pada tabel 1. Rentang usia pasien dari $0-60$ bulan, dimana paling banyak pada rentang usia 0-12 bulan yaitu sebanyak 15 pasien (57,69\%). Dari 26 pasien ini, 2 pasien $(7,62 \%)$ yang lahir prematur, dan 24 pasien $(92,30 \%)$ lahir matur. Kemudian berdasarkan jenis kelamin terlihat angka kejadian CVI lebih besar pada laki-laki yaitu 15 orang $(57,6 \%)$ dibanding dengan perempuan 11 orang (42,31\%).

Pada penelitian ini ditemukan etiologi kongenital sebanyak 17 pasien $(65,38 \%)$ dan etiologi 
didapat sebanyak 9 pasien (34,61\%). Etiologi kongenital yang paling banyak adalah hipoksia perinatal sebanyak 5 pasien $(19,23 \%)$ dan etiologi didapat yang paling banyak adalah meningitis sebanyak 8 pasien $(30,76 \%)$. Dari 5 pasien dengan hipoksia perinatal, satu pasien didapatkan hasil CT scan dengan PVL dan 4 pasien dengan gangguan neurologis cerebral palsy. PVL merupakan merupakan bentuk yang paling umum dari kerusakan akibat hipoksia-iskemia perinatal. ${ }^{(10)}$ Bayi prematur dengan hipoksia-iskemia perinatal kemungkinan mempunyai gangguan neurologis berupa cerebral palsy.(6) Dari literatur juga disebutkan bahwa hipoksia-iskemia perinatal merupakan penyebab CVI kongenital yang paling sering pada anak-anak dan infeksi sistem saraf pusat yang paling sering menyebabkan CVI didapat selama masa anak-anak adalah meningitis. (10,11) Penelitian yang dilakukan oleh Khetpal dan Donahue, mereka menemukan hipoksia perinatal sebagai etiologi pada $36 \%$ pasiennya, tetapi mereka menemukan insiden yang rendah dari meningitis terkait dengan CVI. (7) $\mathrm{Hal}$ ini juga hampir sama dengan penelitian yang dilakukan oleh Huo dan kawan-kawan dimana mereka menemukan hipoksia perinatal sebagai etiologi pada $22 \%$ dari pasien CVI. (15)

Pada penelitian ini gangguan okular terkait dengan penderita CVI terlihat pada 7 pasien yaitu atrofi optik kedua matapada 4 pasien, nistagmus pada 2 pasien dan eksotropia pada 1 pasien. Atrofi optikyang terjadi pada pasien CVI terjadi akibat descending optic atrophy (dari degenerasi transsynaptic). (8) Pada penelitian ini, semua pasienpasien dengan atrofi optikdilakukan pemeriksaan CT Scan dan ditemukan gambaran perdarahan intra kranial, atrofi cerebri, brain atrofi dengan hidrosefalus non obstruktif, dan atrofi lobus frontal dan serebelum. Usia pasien CVI dengan atrofi optik ini yaitu 5 bulan, 13 bulan, 14 bulan, dan 16 bulan. Nistagmus ditemukan pada 2 pasien dengan etiologi yaitu meningitis purulenta dan infeksi intrauterin toksoplasmosis. Kemudian ditemukan juga eksotropia $45^{\circ}$ mata kanan pada satu pasien, dengan gambaran CT scannya berupa brain atrophy dengan hidrosefalus non obstruksi. Penelitian yang dilakukan oleh Khetpal dan Donahue, mereka menemukan kelainan okular yang paling banyak adalah strabismus khususnya eksotropia pada $41 \%$ dari pasiennya sedangkan atrofi optik hanya ditemukan pada $25 \%$ pasien. (7) Sedangkan penelitian yang dilakukan Huo dan kawankawan dimana mereka menemukan esotropia dan eksotropia terjadi pada 37\% dari pasien CVI. (15)

Kebanyakan anak dengan CVI memiliki masalah neurologis tambahan, termasuk cerebral palsy, retardasi mental, epilepsi, dan mikrosefali. Diagnosa dari gangguan neurologis pada pasien CVI ini didapatkan dari bagian anak. Tingginya prevalensi kelainan neurologis pada pasien CVI menunjukkan bahwakerusakan difus di seluruh otakmenyebabkan kelainan di jalur visual posterior. ${ }^{(10)} \mathrm{Hal}$ ini dikonfirmasi dengan pemeriksaan CT scan kepala untuk melihat kelainan di jalur visual posterior. Namun pada penelitian ini tidak semua pasien dilakukan pemeriksaan CT scan kepala.Pada penelitian ini ditemukan bahwa epilepsi merupakan defisit neurologis terbanyak yang terkait pada pasien CVI. Dari 7 pasien dengan gangguan neurologis epilepsi hanya 3 pasien yang dilakukan pemeriksaan imaging yaitu dengan gambaran brain atrophy dengan hidrosefalus non obstruksi, atrofi serebri dan serebelum, dan atrofi serebri. Hasil ini hampir sama dengan penelitian yang dilakukan oleh Khetpal dan Donahue, dimana epilepsi merupakan defisit neurologis terbanyak. ${ }^{(7)}$ Cerebral palsy ditemukan pada 4 orang pasien, namun pada keempat orang pasien ini tidak dilakukan pemeriksaan imaging. Mikrosefali ditemukan pada 2 orang pasien, hal ini didapat dari pemeriksaan klinis dan didukung dengan gambaran CT scan.

Pemeriksaan imaging pada pasien CVI digunakan untuk mengidentifikasi penyebab CVI yang dapat mendukung diagnosa dan untuk menentukan kemungkinan prognosis pada pasien CVI. (10) Pada penelitian ini dari 26 pasien, hanya 15 pasien yang dilakukan pemeriksaan imaging yaitu pemeriksan CT Scan kepala, mayoritas dari hasil CT Scan tidak normal. Kelainan yang paling banyak ditemukan adalah brain atrophy yang terdiri dari atrofi serebral dan serebelum sebanyak 3 pasien, mild brain atrophy sebanyak 3 pasien dan mikrosefali sebanyak 2 pasien.

\section{KESIMPULAN}

Pada penelitian ini ditemukan etiologi kongenital lebih banyak dibandingkan dengan etiologi didapat. Yang paling banyak ditemukan pada etiologi kongenital adalah perinatal hipoksia - iskemia dan pada etiologi didapat adalah meningitis. Gangguan okular terkait dengan CVI yang ditemukan pada penelitian ini adalah atrofi optik, kemudian diikuti dengan nistagmus dan eksotropia.Pada penelitian ini juga ditemukan gangguan neurologis terkait dengan CVI yaitu epilepsi, cerebral palsy dan mikrosefali.

\section{DAFTAR PUSTAKA}

1. Carden SM, Good WV. Cortical Visual Impairment. In: Wright KW, Spiegel PH, Thompson LS. (eds). Handbook of Pediatric Neuro-Ophthalmology. USA: Springer; 2006. pp. 247-254.

2. Rudanko SL, Fellman V, Laatikainen L. Visual Impairment in Children Born Prematurely from 1972 through 1989. AmericanJournal of Ophthalmology. 2003; 110: pp. 1639-1645.

3. Fulton $A B$, Moskowitz A, Eklund SE, Hansen RM. Visual Impairment in Infants and Young Children. In: Albert DM, Miller JW. (eds). Principles and Practice of Ophthalmology. 3rd edtion. Elsevier; 2008. pp 4225-4240.

4. Rogers M. Visual impairment in Liverpool: prevalence and morbidity. Archives of disease in childhood. 1996;74: pp 299-303.

5. Chong CF, Dai S. Cross-sectional study on childhood cerebral visual impairment in New Zealand. Journal American Association for Pediatric Ophthalmology and Strabismus. 2014;18: 71-74.

6. Good WV, Martin TD. Evaluation of the Apparently Blind Child. In: Wilson ME, Saunders RA, Trivedi $\mathrm{RH}$. (eds). Pediatric Ophthalmology Current Thought and A Practical Guide. Verlag Berlin Heidelberg: Springer; 2009. pp 73-84.

7. Khetpal V, Donahue SP. Cortical Visual Impairmnet: Etiology, Associated findings, and Prognosis in a Tertiary Care Setting. Journal 
American Association for Pediatric Ophthalmology and Strabismus. 2007; 11: pp. 235-239.

8. Skuta GL, Cantor LB, Weiss JS. Decreased Vision in Infants and Chlidren. In: Skuta GL, Cantor LB, Weiss JS (eds). Pediatric Ophthalmology and Strabismus. San Fransisco: American Academy Of Ophthalmology; 2014-2015. pp. 191-192.

9. Swift SH, Davidson RC, Weems LJ. Cortical Visual Impairment in Children: Presentation Intervention, and Prognosis in Educational Settings. Teaching Exceptional Children Plus. 2008;5: pp 1-14.

10. Good WV, Jan JE, deSA L, Barkovitch AJ, Groenveld M, Hoyt CS. Cortical visual impairment in children: a major review. Survey Ophthalmology. 1994;38: pp 351-364.

11. Lambert SR. Cerebral Visual Impairment. In: Wright KW. Pediatric Ophthalmology and Strabismus. St Louis: Mosby; 2000. pp 801-805.

12. Jacobson LK, Dutton GN. Periventricular Leukomalacia: An Important cause of Visual and Ocular Motility Dysfunction in Children. Survey of Ophthalmology. 2000; 45: pp. 1-13.

13. Smith J. Cortical Visual Impairment. Development Medicine and Child Neurology. 2007;25: 755-762.

14. Dutton GN, Jacobson LK. Cerebral Visual Impairment in Children. Semin Neonatology. 2001;6: pp 477-485.

15. Huo R, Burden S, Hoyt CS, Good WV. Chronic cortical visual impairment in children: etiology, prognosis, and associated neurological deficits. British Journal Ophthalmology. 1999;83: pp 670675. 